\title{
O PÓS-MODERNO EM QUESTÃO: A SOCIEDADE DOS MEDIA E A CRÍTICA CONTEMPORÂNEA
}

\author{
Antonio Glaudenir Brasil Maia ${ }^{1}$ [UVA]
}

\begin{abstract}
Resumo: A problemática "O Pós-moderno em questão: a sociedade dos media e a crítica contemporânea" suscita a reflexão sobre a comunicação na experiência do presente, considerado pressuposto basilar para se compreender a sociedade pós-moderna como a sociedade dos media. O referencial teórico-filosófico centra-se nas postulações do filósofo italiano Gianni Vattimo e a postura de alguns pensadores como Jamenson e Eagleton, nominados no quadro da crítica contemporânea ao pós-moderno. Alguns acontecimentos e mudanças, apontadas por Vattimo, evidenciam o caráter emancipativo assumido na pós-modernidade a partir da atuação dos mass media, a saber: a) a libertação e o reconhecimento das culturas particulares, rompendo assim com o eurocentrismo; b) o próprio surgimento da diversidade de visões de mundo, com suas propriedades e dialetos. Os media promovem assim um novo sentido cultural para a pós-modernidade, configurado pela presença de culturas particulares, com seus dialetos próprios. Entretanto, para a crítica contemporânea a pós-modernidade não significa nenhuma novidade, apenas representa os interesses do poder econômico da sociedade atual: seja o pósmoderno a lógica cultural do capital de Jameson, seja o mundo dos negócios de Eagleton. Encontramo-nos diante de posições distintas: uma de cunho estritamente filosófica e uma de tonalidade econômico-políticosocial? Isso define a trajetória parcial de nossa reflexão nesse artigo.
\end{abstract}

\section{Palavras-chave}

Pós-modernidade. Sociedade dos media. Comunicação. Emancipação. Cultura.

\begin{abstract}
The problem related to "The postmodern concern: media-centered society and contemporary criticism" raises the reflection about the experience of communication at present, which is considered a fundamental assumption to understand the post-modern society as a media-centered society. The theoretical-philosophical framework focuses on the considerations of the Italian philosopher Gianni Vattimo and the position of thinkers such as Jameson and Eagleton, regarded as contemporary critics of postmodernism. Some events and changes, highlighted by Vattimo, point to the emancipatory character of the performance of mass media in postmodernity, namely: a) freedom and acknowledgement of particular cultures, thus breaking down Eurocentrism; b) the emergence of worldview diversity followed by specific properties and dialects. Thus, the media promote a new cultural meaning in post-modernity, influenced by the presence of particular cultures and their own dialects. However, post-modernity is not a novelty for contemporary criticism; it only represents the interests of the economic power holders of the present society: whether post-modernism is the cultural logic of late capitalism of Jameson or the world of business of Eagleton. Are we facing two distinct positions, namely, a strictly philosophical one and an economic-social-political one? This partially presents what shall be discussed in the article.
\end{abstract}

\section{Keywords}

Post-modernity. Media-centered society. Communication. Emancipation. Culture.

\section{Introdução}

É muito comum hoje em dia encontrarmos o uso do termo pós-modernidade e suas derivações em discursos e campos de atuação humana que vão desde a cultura, a arquitetura, o educacional, a ciência e, principalmente, a reflexão filosófica. Parece-nos que esse uso "indiscriminado" nos discursos atuais tem a pretensão de fugir a todo e qualquer

\footnotetext{
${ }^{1}$ Doutor em Filosofia. Professor de Filosofia na UVA e no mestrado na UECE. Coordenador do Grupo de Pesquisa Filosofia da Religião [Gephir/CNPq]. Coordenador do Gt Ética e Cidadania da ANPOF. Atualmente realiza estágio pós-doutoral no Programa de Pós-Graduação em Filosofia da UFC/CAPES.
} 


\section{O PÓS-MODERNO EM QUESTÃO: A SOCIEDADE DOS MEDIA...}

Antonio Glaudenir Brasil Maia

esquematismo categorial absoluto e como controvérsia aos discursos proliferados na modernidade.

Talvez isso explique o fato de não haver um consenso entre os mais diferentes discursos em relação à pós-modernidade - o dissenso talvez, se proposital ou não, e a série de significações é de fácil registro. É possível encontrarmos certo compartilhar de ideias referentes ao termo visto como despedida da modernidade e como a assunção de um novo paradigma (vejamos as posturas de Lyotard, de Vattimo), mas também uma nítida atitude de negação, um questionamento sobre a validade do caráter não só epistemológico, mas ético, político, econômico, dentre outros no que diz respeito ao pós-moderno (vejamos, por exemplo, Jameson, Habermas, Eagleton). Parece-nos que a própria polissemia seja algo imanente ao termo (pós-moderno), o que requer uma análise do contexto para o qual se empresta tal termo e, aqui, não temos a pretensão de exaurir o assunto por completo a partir da elaboração de um conceito preciso e que ponha fim a discussão que travamos em nossos dias.

Um dos aspectos importantes na reflexão realizada por Vattimo é o fato de que o autor já de antemão defende a impossibilidade, ou melhor, recusa qualquer tentativa de elaboração de um discurso englobante sobre o mundo - ideal presente também na reflexão de Lyotard expressa na sentença do fim das metanarrativas ${ }^{2}$. A assertiva de Vattimo sobre a experiência pós-moderna e sua relação com o fenômeno da comunicação (sociedade dos media) compreende a intenção de afirmar o pluralismo cultural, a negação da lógica fundamentalista própria dos discursos modernos. Nesta perspectiva, Vattimo defenderá um caráter emancipativo no ethos pós-moderno, reconhecendo que o prefixo "pós” expressa um novo horizonte positivo para o pensamento filosófico ocidental.

Entretanto, para a crítica contemporânea - e aqui designaremos com esta expressão todo o esforço crítico dos autores que rejeitam a ideia de um paradigma pósmoderno - a pós-modernidade não significa nenhuma novidade, nenhuma teoria inaudita, apenas representa os interesses do poder econômico da sociedade atual: seja o pós-moderno a lógica cultural do capital de Jameson, seja o mundo dos negócios de Eagleton, seja o fenômeno da não superação do capitalismo assinalado por Magalhães.

\footnotetext{
${ }^{2}$ A crítica proferida por Lyotard às metanarrativas evidencia sua postura incrédula em relação ao projeto moderno de que mediante o uso adequado da razão esta conduziria a sociedade a um progresso histórico. Por isso, emprega ao termo a ideia de paradigma ausente da crendice quanto aos metarelatos. Cf. LYOTARD, J-F. A Condição Pós-moderna. Rio de Janeiro: José Olympio, 1988.
}

\begin{tabular}{|l|l|l|l|l|}
\hline Revista Dialectus & Ano 2 & n. 5 & Agosto - Dezembro 2014 & p. 1-11 \\
\hline
\end{tabular}




\section{O PÓS-MODERNO EM QUESTÃO: A SOCIEDADE DOS MEDIA...}

Antonio Glaudenir Brasil Maia

Apesar do conflituoso cenário pós-moderno, o que só enseja um maior interesse pelo assunto, e por sua própria significação filosófico-cultural ser posta em questão, principalmente, pela crítica contemporânea bem como pela leitura de Vattimo, algumas problemáticas nos guiarão na reflexão que se segue, a saber: a) Em que sentido a pósmodernidade constitui um novo paradigma? b) Não será ela apenas uma nomenclatura que escamoteia a dominação capitalista, como afirma a crítica contemporânea? c) Será realmente sustentável a hipótese vattimiana de que na sociedade dos media é possível falar de uma certa emancipação, abstraindo-se do fenômeno da massificação como indicou Adorno?

\section{Pós-modernidade e comunicação: a sociedade dos media em Vattimo.}

De início, nossa reflexão depara-se com a tese - não exclusiva em Vattimo - que defende ser a pós-modernidade um novo contexto cultural, o ethos da diversidade, com caráter contraditório ao moderno. O sentido de multiplicidade cultural, para Vattimo, reside no fato de criticar o unitariamente moderno e de defender interpretações mais abertas sobre os acontecimentos. A diversidade de vozes culturais presentes no mundo atual é a expressão máxima do fim do eurocentrismo ${ }^{3}$. Além disso, a pós-modernidade, no dizer de Vattimo, representa a destruição das fronteiras culturais, que somente foi possível devido à interferência das tecnologias informacionais que trouxe o fim da marginalização cultural, tornando pauta de discussão os elementos locais, as minorias. E aqui reside um detalhe fundamental e de extrema necessidade seu realce: Vattimo alerta que, apesar do notável avanço tecnológico obtido em nosso tempo e mesmo reconhecendo o desenvolvimento maquinário, devemos compreender que o que define nossa sociedade atual não é a tecnologia vista enquanto mecanicamente, mas a tecnologia informacional que configura a sociedade pós-moderna como sendo a sociedade da comunicação generalizada.

Vattimo anuncia assim a dissolução dos pontos de vista centrais, reconhecidas no eurocentrismo, associando-a à ação dos mass media. Por isso, Vattimo assinala que a marca do advento da pós-modernidade foi, além do fim do colonialismo e do imperialismo, principalmente, o advento dos mass media. Por conseguinte, a designação de sociedade da comunicação generalizada, segundo Vattimo, é o que caracteriza o pós-moderno. O sentido que para Vattimo exprime a pós-modernidade liga-se ao fato da explosão de culturas pelos

\footnotetext{
3 "Declínio do Ocidente significa, aqui, a dissolução da ideia de um significado e de uma direção unitária da história da humanidade, espécie de alicerce, na tradição moderna, do pensamento ocidental. Este considerava a sua própria civilização como o nível máximo evolutivo alcançado pela humanidade em geral e, baseado nisso, sentia-se chamado a civilizar, mesmo a colonizar, converter, submeter todos os povos com os quais entrava em contato". VATIIMO, G. A Filosofia e o declínio do Ocidente. IN: MENEZES, F. M. e SILVA, J. M. da. Para Navegar no Século XXI. Porto Alegre: Saliera/Edipucrs, 2003.
}

\begin{tabular}{|l|l|l|l|l|}
\hline Qevista Dialectus & Ano 2 & n. 5 & Agosto - Dezembro 2014 & p. 1-11 \\
\hline
\end{tabular}


mass media, pois estamos constantemente ligados e informados sobre o mundo. Após esse acontecimento, tornam-se impossíveis às ideias modernas, principalmente, da centralidade cultural. Isso porque os mass media a caracterizam por uma complexidade de acontecimentos, que deve ser entendida como um entrelaçamento de diversos caracteres culturais expostos ao mundo por aqueles (media). Por isso, afirma que: "Pois bem, eu considero, pelo contrário, que, o termo pós-moderno tem um sentido; e que este sentido está ligado ao fato da sociedade em que vivemos ser uma sociedade da comunicação generalizada, a sociedade dos mass media”. (VATTIMO, 1989, p. 07).

Vattimo procura advertir que, apesar do fim do colonialismo e do imperialismo, a ação dos mass media foi mais decisiva no estabelecimento da impossibilidade de se pensar um curso unitário ${ }^{4}$ para a história. Os meios de comunicação de massa representaram, segundo a ótica de Vattimo, a dissolução das grandes narrativas e promoveram o contrário do que pensava Adorno: este os criticava por perceber que estavam em função da lógica econômica e produziam a homologação da sociedade capitalista ${ }^{5}$. Entretanto, Vattimo [1989, p. 10] adverte que o sentido real da ação dos mass media na sociedade atual não se restringe ao que condenava Adorno.

O que de fato aconteceu, porém, não obstante todos os esforços dos monopólios e das grandes centrais capitalistas, é que a rádio, a televisão, os jornais se tornaram elementos de uma grande explosão e multiplicação de weltanschauungen, de visões de mundo.

Essas visões de mundo expressam, segundo Vattimo, o requerimento do diverso por parte de culturas até então marginalizadas. Longe de o caráter informacional recair sobre os indivíduos impossibilitando-os de compreender o mundo, favorece-os um conhecimento da complexidade dos fatos ocorridos na sociedade atual. Entretanto, segundo Vattimo, nem todos os pensadores aceitam tal possibilidade: afirma-se que a intensificação da comunicação tornou-se suporte para o poder, onde o avanço da tecnologia, mais que propiciar a distribuição da informação, alargou e conservou a propaganda, a publicidade e as ideologias que se

\footnotetext{
${ }^{4}$ Fugir a lógica fundamentalista de uma "história" é pretender superar toda ideologia dominante, reconhecendo que os vencidos, suas vidas e crenças também fizeram parte da coreografia das cenas históricas. Benjamin afirma na tese 14 de sua Filosofia da História que a história contada sempre pelos vencedores pode ser considerada como um tempo homogêneo e vazio. O que deve vigorar é que temos de perceber que a história pode vir à luz de nossas consciências a partir dos vencidos e marginalizados, afirmando que a história pensada pelo prisma de um curso unitário e linear é a representação do passado por determinado grupo ou classe social dominante. Cf. BENJAMIN, Walter. Teses de Filosofia da História. In: Magia e Técnica, Arte e Política. Trad. Sérgio Paulo Rouanet. São Paulo, 1985, p. 230.

${ }^{5}$ Para este pensador, os media provocam e promovem a massificação de nossa sociedade, no sentido de que os mesmos produziram uma homologação geral, mediante o controle, a distribuição e a venda de imagens do mundo aos indivíduos como forma de manter a ordem econômico-social do presente. Cf. ADORNO, T. e HORKHEIMER, M. A Dialética do Esclarecimento [1947]. Rio de Janeiro: Jorge Zahar Ed., 1985, p. 136.
}

\begin{tabular}{|l|l|l|l|l|}
\hline Qovista Dialectus & Ano 2 & n. 5 & Agosto - Dezembro 2014 & p. 1-11 \\
\hline
\end{tabular}


encontram em função dos interesses da classe que domina a sociedade atual. O próprio Vattimo reconheceu tal desvio, mas não perdeu o otimismo quanto à interferência dos media na vida social. O fundamental é que a intensificação da informação tornou impossível pensar uma história universal: com a explosão de culturas abriu-se um novo horizonte de pensamento marcado por uma diversidade de concepção de mundo.

De fato, uma tal possibilidade parece ao alcance da mão: bastaria que os mass media, que são os modos em que a autoconsciência da sociedade se transmite a todos os seus membros, não se deixassem já condicionar por ideologias, interesses de setores, etc., e se tornassem de alguma forma 'órgão' das ciências sociais, se sujeitassem à medida crítica de um saber rigoroso, difundissem uma imagem 'cientifica' da sociedade, precisamente aquela que as ciências humanas estão já em condições de construir. (VATTIMO, 1989, p. 28).

É, nesse sentido, que Vattimo define que o papel da Filosofia na sociedade dos media, onde se desenvolvem diferentes concepções de mundo, é o papel de intérprete como hermenêutica da existência no mundo midiático, da liberalização da interpretação e, até mesmo, dos (des)avanços dos mass media, entre outros aspectos. A intensificação do sistema de informação incorre na multiplicação das 'agências interpretativas' que paradoxalmente se apresentam como interpretativas. Tais agências, segundo Vattimo, permitem a construção de nossa imagem do mundo, produzindo uma redução substancial do [peso] sentido da realidade, em suma, da mediatização da cultura, o caráter retórico da própria história.

A assertiva vattimiana sobre a experiência pós-moderna e a sua relação com o fenômeno da comunicação compreende a intenção de afirmar o pluralismo cultural. É bom destacarmos, contudo, que a afirmação da pluralidade cultural não incorre no perigo do relativismo, como acusam os adversários do pensamento de Vattimo.

O puro relativismo cultural é impotente diante as avaliações, e torna uma espécie de justificação universal de cada horizonte cultural. Se eu, ao contrário, concebo a pluralização dos universos culturais como um processo que tem um fio condutor, em nome deste fio condutor poderei preferir uma sociedade pluralista. Não preferir um horizonte pluralista onde cada um age como crer, mas preferir uma sociedade onde o pluralismo é efetivamente em ato: diante ao regime de Khomeini saberá avaliar e escolher. É uma diferença sutil, mas essencial ${ }^{6}$.

Nessa sociedade existe uma pluralidade de culturas particulares, há o contato e a possibilidade de existência de outros "modos de vida" e "dialetos". Por enquanto, o efeito da ação dos media é algo constatável e definido como uma experiência de 'emancipação', que configura a pós-modernidade, consiste na libertação das diferenças, dos elementos locais, dos

6 VATTIMO, Gianni. Pensiero Secolarizzato. In: Poliedro, 9-10, 1987, p. 78. Consultar também ANTISERI, Dario. Le Ragioni del Pensiero Debole. Domanda a Gianni Vattimo. Roma: Burla, 1995, p. 49; TEIXEIRA, Evilázio. A Fragilidade da Razão: pensiero debole e niilismo hermenêutico em Gianni Vattimo. Porto Alegre: EDIPUCRS, 2005, p. 138.

\begin{tabular}{|l|l|l|l|l|}
\hline Govista Dialectus & Ano 2 & n. 5 & Agosto - Dezembro 2014 & p. 1-11 \\
\hline
\end{tabular}


dialetos.

O efeito emancipador da libertação das racionalidades locais não é, todavia, apenas o de garantir a cada uma delas um mais completo reconhecimento e 'autenticidade'; como se a emancipação consistisse em manifestar finalmente aquilo que cada um é 'verdadeiramente' [...]: negro, mulher, homossexual, protestante, etc. O sentido emancipador da libertação das diferenças e dos 'dialectos' consiste mais no efeito global de desenraizamento que acompanha o primeiro efeito de identificação. Se falo o meu dialecto, finalmente, num mundo de dialectos entre outros, se professo o meu sistema de valores - religiosos, estéticos, políticos, étnicos - neste mundo de culturas plurais, terei também uma consciência intensa da historicidade, contingência, limitação, de todos estes sistemas, a começar pelo meu. (VATTIMO, 1992, p. 15).

A concepção vattimiana de emancipação consiste na descentralização de toda posição na história que, com base na ação dos mass media, foi possível o contato entre múltiplas culturas particulares. Estas, inseridas no mundo da comunicação generalizada, se expressam em suas condições próprias [étnicas, religiosas, estéticas, morais...], no sentido de "tomar a palavra", de serem reconhecidas como tais, rompendo com toda e qualquer orientação de uma "forma única" de cultura-humanidade. A multiplicação da comunicação implica, seguindo a leitura de Vattimo, esse tomar parte do diálogo, do "tomar a palavra" que tem o significado de explosão de subculturas, da pluralidade de culturas.

Em suma, o mundo da comunicação generalizada permite o surgimento da multiplicidade de racionalidades 'locais', minorias étnicas, sexuais, religiosas, estéticas, etc. A experiência pós-moderna é, com efeito, uma experiência na qual se amplia o valor da palavra, da comunicação, do discurso, impossibilitando que sejam (re)construídas novas visões totalizantes, deixando falar cada vez mais as vozes periféricas, as minorias. A reflexão vattimiana sobre a pós-modernidade como sociedade dos media não deve ser compreendida, por isso, como uma simples fenomenologia dos media e da comunicação nem tampouco considerada como um modo oportuno de atualidade filosófica.

É importante destacarmos as mais recentes palavras de Vattimo apresentadas no livro La Vita dell'altro. Bioetica senza metafisica [2006b], em especial, o que trata o capítulo La rete e il postmoderno. Retoma-se a tese de que a leitura da maioria dos autores críticos da tecnologia permaneceu restrita ao aspecto mecânico, o que implicou uma postura 'crítica' ao mundo da racionalidade técnica. Dessa forma, a Modernidade foi caracterizada como a época do motor e da indústria ao passo que pós-modernidade, para Vattimo, tem sentido na dissolução do modelo do motor. Com isso, o reconhecimento da 'rede', isto é, a dimensão mecânica é substituída pela dimensão da informatização da sociedade.

\begin{tabular}{|l|l|l|l|l|}
\hline Govista Dialectus & Ano 2 & n. 5 & Agosto - Dezembro 2014 & p. 1-11 \\
\hline
\end{tabular}


A pós-modernidade, pensada como sociedade dos media [sociedade transparente], melhor dizendo, como sociedade da rede [sociedade digital] tem na reciprocidade da comunicação a deslegitimação da ideia da existência de uma instância suprema, de um fundamento absoluto. Diante dos avanços da sociedade digital, da telemática, Vattimo declara que o papel da Filosofia sofreu uma mudança substancial. Em outros termos, ele afirma que quando a imagem da rede substitui o modelo do motor, a postura da Filosofia muda ante as implicações da tecnologia da informação para a existência na pós-modernidade. Desse modo, “[...] o instaurar-se da 'rede' interpela a Filosofia a um apelo muito mais substancial, aquele de repensar a existência e a essência mesma do pensamento fora dos modelos herdados da modernidade" (VATTIMO, 2006, p. 193). Todos esses aspectos não foram levados em consideração por alguns críticos da pós-modernidade, restringindo o foco para a associação que fazem da época pós-moderna e a sociedade capitalista.

\section{O Pós-moderno e a Crítica Contemporânea}

Fredric Jameson, um dos mais expoentes críticos do pós-moderno, tem como objeto de sua reflexão a transformação da cultura em mercadoria, o que é bem expresso no titulo de seu livro Pós-modernismo: a lógica cultural do capitalismo tardio [1991]. Em tal obra, Jameson sustenta que a cultura se tornou um produto no pós-modernismo ${ }^{7}$ : a cultura se torna objeto de consumo, a lógica que abrange toda a dimensão existencial, um puro obscurecimento da consciência. É, por isso, que sua pretensão é explicitar criticamente a forma como a cultura se insere no capitalismo, uma leitura dos tempos pós-modernos à luz, digamos, do marxismo.

Crítico da cultura, Jameson utiliza uma abordagem totalizante sobre a temática do pós-modernismo, como forma de estabelecer uma leitura crítica coerente em busca da superação da dominação cultural dos tempos atuais. O que é fundamental, para ele, é avaliar a problemática da produção cultural $^{8}$, levando-se em conta as determinantes do sistema capitalista sobre tal produção. Já anuncia que - apesar da existência da diversidade de teorias e

\footnotetext{
${ }^{7}$ Cf. JAMESON, Fredric. Pós-modernismo: alógica cultural do capitalismo tardio [1991]. São Paulo: Ática, 2002, p. 14 .

${ }^{8}$ Fridman assinala que se identifica em Jameson a ideia de sinonímia entre pós-moderno e 'capitalismo da midia', o que se conclui que a linguagem midiática altera os modos de vida. O que mais especificamente se reconhece é a dimensão de 'des-diferenciação' entre cultura e economia que se efetiva no pós-modernismo enquanto atmosfera cultural do capitalismo. Cf. FRIDMAN, Luis Carlos. Pós-modernidade: sociedade da imagem e sociedade do conhecimento. In: História, Ciência, Saúde - Manguinhos, V (2), pp. 353-75, jul-out. 1999.
}

\begin{tabular}{|l|l|l|l|l|}
\hline Qovista Dialectus & Ano 2 & n. 5 & Agosto - Dezembro 2014 & p. 1-11 \\
\hline
\end{tabular}


de discursos, o que torna conflituoso o próprio conceito ${ }^{9}$ - a pós-modernidade não representa uma nova época, não é uma teoria perfeita e pura, totalmente distinta da tradição, pois “[...] o pós-modernismo não é a dominante cultural de uma ordem social totalmente nova (sob o nome de sociedade pós-industrial, esse boato alimentou a mídia por algum tempo), mas é apenas reflexo e aspecto concomitante de mais uma modificação sistêmica do próprio capitalismo" (JAMESON, 1991, p. 16).

Assim percebemos que o autor afirma ser impossível o pós-modernismo representar uma nova época, pois reconhece que em sua essência se encontra a marca da lógica do capital, ou seja, o pós-moderno representa a nova etapa de tal lógica ou ser ele mesmo à própria lógica enquanto dominante cultural. Desse modo, Jameson defende ser o pós-modernismo a dominante cultural, pois tem função social no sistema econômico o que possibilita a análise crítica de situação atual realizada na obra citada. Entretanto, rejeita a designação de 'pós-industrial' para a época atual, prefere falar de capitalismo multinacional. A concepção de pós-modernismo, para ele, é histórica por representar a dominante cultural da lógica do capitalismo tardio, isto é, a cultura submersa na lógica da mercadoria. Por isso, é que Jameson (1991, p. 402) ressalta que o pós-modernismo não é simplesmente uma categoria especificamente cultural, como muitos interpretaram, mas “[...] se destina a nomear um 'modo de produção' no qual a produção cultural tem lugar funcional especifico".

A pretensão real de Jameson, que merece nossa atenção, foi salvaguardar o pensamento crítico contra a alienação característica do pós-modernismo na sociedade capitalista, o que passa pelo esclarecimento do que seja realmente tal contexto para ele. Isso não valida a insinuação de que Jameson seja um simpatizante ${ }^{10}$ do pós-modernismo, ao contrário, o que constatamos é que ele acreditou ser melhor analisá-lo seriamente em vez de rejeitá-lo por razões simplistas.

Eu também, como todo mundo, fico às vezes muito entediado com o slogan 'pósmoderno', mas quando começo a me arrepender de minha cumplicidade com ele, a deplorar seu uso errôneo e sua notoriedade e a concluir, com alguma relutância, que

\footnotetext{
9 “Com relação a pós-modernismo, não procurei sistematizar um uso ou impor um significado convenientemente conciso e coerente, uma vez que esse conceito não só é contestado, mas é também intrinsecamente conflitante e contraditório. Vou argumentar que, por bem ou por mal, não podemos não usa-lo. [...] não é algo que se possa estabelecer de uma vez por todas e, então, usa-lo com a consciência tranquiila. $\mathrm{O}$ conceito, se existe um, tem que surgir no fim, e não no começo de nossas discussões." Cf. JAMESON, op.cit. p. 25.

${ }^{10}$ Isto fica claro em diversas passagens da obra de Jameson e que aqui nos remetemos as seguintes: na página 17 , quando diz que: "[...] fingi acreditar que o pós-moderno é tão diferente como pensa ser e que constitui uma ruptura em termos de cultura, e de experiência, que vale a pena explorar em maiores detalhes." E também na página 303, ao afirmar que: "[...] em termos culturais, escrevo como um consumidor do pós-modernismo relativamente entusiasmado, ou pelo menos que gosta de algumas de suas manifestações: gosto da arquitetura...”. Cf. Idem.
}

\begin{tabular}{|l|l|l|l|l|}
\hline Qovista Dialectus & Ano 2 & n. 5 & Agosto - Dezembro 2014 & p. 1-11 \\
\hline
\end{tabular}




\section{O PÓS-MODERNO EM QUESTÃO: A SOCIEDADE DOS MEDIA...}

Antonio Glaudenir Brasil Maia

ele levanta mais problemas do que resolve, eu me vejo parando para pensar se qualquer outro conceito poderia dramatizar essas questões de forma tão eficiente e econômica. (JAMESON, 1991, p. 413).

Eagleton, numa atitude semelhante à de Jameson, afirma que o pós-modernismo expressa a íntima relação entre as formas simbólicas e as formas econômicas presentes no contexto da sociedade capitalista atual. O horizonte que se abre é apenas a "lógica do mercado" transformou tudo em mercadoria em que "[...] o termo 'pós' se significa alguma coisa, significa negócios, como sempre, só que agora um pouco mais”, adverte Eagleton (1993, p. 275).

$\mathrm{Na}$ esteira dessa reflexão crítica se encontra a ideia de que a pós-modernidade é um fenômeno inerente da mundialização o que, segundo Magalhães (2004), Jameson chamou de o "capitalismo em sua fase avançada", ", que equivale a dizer que o pós-moderno representa a lógica de dominação do capital por outros meios. Dessa forma, se defende a tese de que o pós-moderno representa a insuperabilidade do capitalismo, pois no atual estágio o processo de mercadorização capitalista se realiza com o codinome pós-modernismo - a ideia da não-distinção entre a economia e a cultura, onde a arte e o saber se tornam mercadorias.

[...] a hipótese de que a pós-modernidade nada mais é do que o modelo sóciopolítico e cultural do capitalismo na época de sua globalização total, o que me leva a concluir, da mesma forma, que o marxismo é uma filosofia imprescindível de nosso tempo, ainda que, isoladamente, não dê conta de toda a realidade. (MAGALHÃES, 2005, p. 193).

Nesse sentido, a leitura crítica sobre a pós-modernidade a classifica não como uma nova teoria, mas como uma lógica que legitima o atual estágio do capitalismo. O que verificamos é a própria negação da pós-modernidade, considerada a época do capital globalizado e, ao mesmo tempo, se afirma a presença do pensamento de Marx, ou seja, se reporta à reflexão crítica marxista como ferramenta para a superação da pós-modernidade. A maior parte dos teóricos que de fato se debruçaram ['criticamente'] sobre a problemática da pós-modernidade se manteve no estreito horizonte de [estabelecer] uma convergência e, até mesmo, uma complementaridade entre cultura, pós-modernidade e sociedade pós-industrial. Diversas foram as tentativas, e não podemos perder de vista as suas respectivas peculiaridades e contribuição ao debate, entre as quais, as múltiplas leituras sobre o pós-moderno, são precedidas pela maneira como tais teóricos compreenderam a sociedade contemporânea [capitalista].

\section{Considerações Finais}

${ }^{11}$ Cf. MAGalhães, Fernando. Tempos Pós-modernos: a globalização e as sociedades pós-industriais. São Paulo: Cortez, 2004, p. 63.

\begin{tabular}{|l|l|l|l|l|}
\hline Q Rovista Dialectus & Ano 2 & n. 5 & Agosto - Dezembro 2014 & p. 1-11 \\
\hline
\end{tabular}


Quando Vattimo se apropria da ação dos mass media, afirmando que promoveram o ocaso do pensamento moderno e, especialmente, promoveram o surgimento de diversas visões de mundo, assume uma postura positiva em relação às técnicas de informação que marcam a sociedade pós-moderna. Além disso, define ser tal sociedade o ethos do heterotopismo, da presença de múltiplas culturas, que tem como efeito a dissolução de qualquer pretensão de centralismo cultural - o eurocentrismo. Sem nenhuma dúvida, os mass media modificaram o sentido da existência humana, tornando a pós-modernidade uma época distinta, a sociedade da comunicação generalizada. A crítica pós-moderna de Vattimo pretende ser uma leitura hermenêutica dos mecanismos legitimadores da sociedade moderna.

Entretanto, no que tange as objeções quanto à ação dos media, o próprio Vattimo afirmou existência dos grandes monopólios econômicos, o que implicou no fato de reconhecer que os media estão a "serviço" de alguns interesses. Apesar desta atitude de Vattimo, não podemos deixar de perceber uma certa incongruência ou, sendo mais claro, uma lacuna em sua reflexão, pois ele deveria dedicar um maior espaço em suas obras para tal problemática. Com isso, não negamos o poder crítico de seu pensamento e sua contribuição para o pensamento filosófico atual.

Como o mundo contemporâneo é o momento dos media, onde se desenvolvem diferentes concepções de mundo, a filosofia assume o papel de intérprete. E aqui a filosofia de Vattimo tem muito a contribuir, seja na sua crítica a metafísica, seja na sua análise hermenêutica da existência, sejam as suas reflexões sobre a religião e a estética, dentre outros aspectos. Como o pensamento filosófico ocidental tem diversas correntes, o pensiero debole de Vattimo figura umas das marcas do pós-moderno, o que o faz compreender de maneira diversa os acontecimentos: se para Jameson a estetização configura-se como colonização do inconsciente, para Vattimo, ao contrário, a estetização representa algo positivo para a cultura atual, pois possibilita as mais diversas manifestações; e se para Marx os filósofos não transformaram o mundo, apenas divagaram em especulações, para Vattimo, os filósofos, sim, se limitaram em descrevê-lo, porém, adverte que chegou a hora de interpretá-lo. Portanto, para Vattimo, a hermenêutica representa a marca principal da pós-modernidade, por ser esta entendida como a sociedade dos media, onde a reflexão filosófica se depara com a dimensão histórica própria da pós-modernidade, quando a ação dos media dissolve a cosmovisão eurocêntrica, em que o próprio pensamento filosófico pós-moderno deve impossibilitar que sejam (re)construídas novas visões totalizantes, deixando falar cada vez mais as vozes periféricas, as minorias.

\begin{tabular}{|l|l|l|l|l|}
\hline Qovista Dialectus & Ano 2 & n. 5 & Agosto - Dezembro 2014 & p. 1-11 \\
\hline
\end{tabular}




\section{Referências}

ADORNO, T. e HORKHEIMER, M. A Dialética do Esclarecimento [1947]. Rio de Janeiro: Jorge Zahar Ed., 1985.

BENJAMIN, Walter. Teses de Filosofia da História. In: Magia e Técnica, Arte e Política. São Paulo, 1985.

EAGLETON, T. A Ideologia da Estética: da polis ao pós-modernismo. Rio de Janeiro: Jorge Zahar Ed, 1993.

FRIDMAN, Luis Carlos. Pós-modernidade: sociedade da imagem e sociedade do conhecimento. In: História, Ciência, Saúde - Manguinhos, V (2), pp. 353-75, jul-out. 1999.

GOERGEN, Pedro. Pós-modernidade, ética e educação. São Paulo: Autores Associados, 2001.

JAMESON, Fredric. Pós-modernismo: alógica cultural do capitalismo tardio [1991]. São Paulo: Ática, 2002.

LYOTARD, J-F. A Condição Pós-moderna. Rio de Janeiro: José Olympio, 1988.

MAGAlHÃES, Fernando. Tempos Pós-modernos: a globalização e as sociedades pósindustriais. São Paulo: Cortez, 2004.

- O Discurso Filosófico da Pós-modernidade: a filosofia do espetáculo contra o marxismo. In: Revista de Ciências Sociais. UNISSINOS, vl 41, n. 3, set-dez., 2005

MARX, K. A Ideologia Alemã. São Paulo: HUCITEC, 1996.

VATTIMO, G. O fim da modernidade: hermenêutica e niiilismo na cultura pós-moderna [1985]. São Paulo: Martins Fontes, 1996.

Nichilismo ed emancipazione. Etica, política, diritto. Milano: Garzanti, 2003

As aventuras da diferença: o que significa pensar depois de Heidegger e Nietzsche

[1980]. Lisboa: Edições 70, 1988.

- Sociedade transparente [1989]. Lisboa: Relógio D’Água Editores, 1992.

Etica dell'Interpretazione. Torino: Rosenberg \& Sellier, 1989.

Para Além da Interpretação [1994]. Rio de Janeiro: Tempo Brasileiro, 2001.

A Filosofia e o declínio do Ocidente. In: MENEZES, F. M. e SILVA, J. M. da. Para

Navegar no Século XXI. Porto Alegre: Saliera/Edipucrs, 2003.

\begin{tabular}{|c|c|c|c|c|}
\hline Rovista Dialectus & Ano 2 & n. 5 & Agosto - Dezembro 2014 & p. $1-11$ \\
\hline
\end{tabular}

